\title{
Os Livros Brasileiros de 1944
}

Comentou-se bastante que o ano de 1944 na história da literatura brasileira foi "bem triste". Há entretanto um número de publicaçóes tanto de autores consagrados como de jovens escritores que merecem atenção.

Jorge Amado, que aos 16 anos de idade começou a escrever e que apesar de muito jovem ainda tem uma longa lista de trabalhos publicados, continua a historia do cacau começada no seu livro Terras do sem fim, na sequela São Jorge dos Ilhéus. Enquanto que alguns homens maus de sua primeira novela sobrevivem nessa última, mesmo que ainda exista luxuria e violência em abundância, a cena transportase para as maquinações dos exportadores, a suas manipulações de preços e esquemas vitoriosos para espulsar os proprietários das plantações de cacau de suas propriedades e seus poderes políticos. A Clecadência da sociedade capitalista na sua fase de esplendor e a sua insuficiência em face do desastre, constituem o assunto da novela que chega quasi a pregar dogmáticamente que o comunismo oferece a única solução para o caso. Muitas cenas fortes, algumas sensacionais, aliviam a análise econômica que o próprio autor receiava que afetasse a popularidade desta novela. De acordo com algumas antigas e bem estabelecidas definições da forma novelesca, nem os problemas financeiros de ficção, nem a sequência interessante de uma série de cenas, tomarão o lugar do desenvolvimento do estudo profundo dos caracteres.

Dionelio Machado, psiquiatra e presidente da filial da Associação de Escritores no Rio Grande do Sul, não tem produzido muito desde que the foi conferido em 1935 um premio pelo trabalho $O s$ Ratos. Houve durante êsse ano não só uma nova edição de $O s$ Ratos 
como também a publicação pela editora José Olimpio, de Desolação, que se assemelha tanto à primeira novela como à intermediária, $O$ louco de Catí, com sua atmosfera de pesadelo. Da mesma forma que em O louco, mistura-se nessa novela o ponto de vista psiquiátrico com o radicalismo do trabalho e suas lutas com a polícia. Além de bem escrito, o livro tem valor como documento social.

Uma outra novela, também do sul e pertencente à escola de protesto social, é Porta Fechada, pelo jovem escritor Cyro Martins. Foi considerada como promissora. Martins é um autor que tem futuro.

É necessário não esquecer que muitos livros são escritos, mas não são publicados e outros não chegam a ser escritos porque os autores sabem que não poderiam nunca obter publicação. Essa situação não tem nada a ver com os standards literários pois os editores não exigem demais a êsse respeito, mas têm por base considerações políticas.

Cascalho, um estudo de ficção sôbre a região produtora de diamantes, em sua estrutura social, elementos étnicos e seus crimes e paixôes, apareceu no fim do ano. $\mathrm{O}$ autor é Herberto Salles. Vê-se que leu com grande proveito as novelas de Jorge Amado e José Lins do Rego. E mais facil entretanto, copiar a violência e emoções empregadas por êsses escritores, do que sua pericia, e Salles não foi tão feliz ao arranjar que seu jovem e belo heroi escrevesse uma longa carta indiscreta analisando as energias sociais e econônicas da região de maneira que viesse a expor suas próprias idéias e precipitasse a violência reacionária. A novela é longa e deixa um tanto a desejar em estilo, mas não se deve desanimar um ardoroso estudante da vida brasileira.

Encontra-se violência da maneira mais melodramática em Santa Clara, pelo Dr. Novelli Junior. Desonestidades e monopólio erguem suas feias cabeças na cidade de Santa Clara logo que o heroi, um jovem médico, propõe-se a fazer uma obra social e honesta com um hospital ou a sua própria casa remodelada afim de acudir à necessidade urgente de cuidados médicos de uma cidade de interior. Talvez os fatos se dêm com nessa novela, mas Novelli dificilmente o faz crer.

O título do livro de Floriano Gonçalves, Lixo, é o bastante para despertar revulsão nos brasileiros. $\mathrm{O}$ assunto, de acordo com o título, trata da vida dos lixeiros, da infância, amor o doença na promiscuidade em que vivem. Encontra-se nessa novela um naturalismo ultrajante. Assim como todas no gênero, é proveitosa ao estudante, quer 
da lingua ou da vida brasileira, porém cria um sério problema quanto ao programa de traduçãa - o mesmo problema que preocupa os conservadores quando se trata de traduzir Grapes of Wrath ou Sanctuary. Uma boa parte da literatura brasileira, da qual o Brasil deveria orgulhar-se, apresenta o país em todos os set1s matizes, menos sob a luz agradável que desejaria o turismo. Que se poderá fazer quanto a isto, internacionalmente falando?

Ésse problema é ainda mais delicado num caso como Suite $N^{o} 1$, o primeiro livro da série de sketches sôbre a vida brasileira, "casos", anedotas de excentricidade, passagens irônicas de Brasiliana que lembra a famosa Americana da Mercury do Snr. Mencken. Essas coisas são tão leves, mas feitas com tamanha perfeição, que se cobiça para os leitores americanos, porém, sob uma grande apreensão quanto à atitude dos brasileiros em face do seu aparecimento no palco internacional. Outras Suites são esperadas com anciedade do escritor talentoso e de fina sensibilidade: Marques Rebelo.

Almir de Andrade é bem conhecido como tradutor, profesor de direito, crítico e ensaista no campo de sociologia e psicologia; mantém também um cargo importante no D. I. P. Sómente com um milagre de energia como a sua, pôde achar tempo para lançar uma novela apesar de todas as restantes atividades. Seu livro, Duas Irmãs (José Olimpio, 1944), é um interessante estudo de psicologia feminina. Almir promete que as histórias de suas personagens principais proseguirão em outros volumes.

Dois novelistas recentes que surgiram mais ou menos ao mesmo tempo são, Xavier Placer (com A Escolha) e Fernando Sabino (com $A$ Marca) . O tema do primeiro possue pouca novidade além do ambiente brasileiro. Trata da indecisão de um jovem seminarista quanto à sua vocação e acaba por decidir que não nasceu para o sacerdócio. Uma verdadeira luta espiritual não é apresentada ao leitor e certa aridez caracteriza toda a história. A idéia de Sabino sôbre os personagens condenados por hereditariedade à libertade sexual ou infidelidade (em vez de simplesmente ao crime ou à doença mental), embora seja de valor duvidoso quanto à biologia, encerra real mérito como estudo psicológico.

Convites de viajem aos Estados Unidos produziram dois uteis volumes, sendo um do Dr. Oswaldo Cabral, de Florianapolis, e outro por Pedro Calmon, do Rio. Apesar do fato de Calmon ter sido recentemente eleito presidente da Academia Brasileira de Letras, êsses 
livros ilustrados, honestọ e justos, não podem, nem um nem outro, ser considerados obra de significação literária. Seremos felizes, entretanto, si ambos os volumes tiverem muitos leitores, pois suas páginas pessuem informações uteis e frequentemente distraem. O título de Cabral é Terra da Liberdade; o de Calmon, Os Estados Unidos de Este a Oeste.

A crítica esteve em boa situação no ano de 1944. Alvaro Lins publicou o terceiro volume dos seus artigos críticos Jornal de Critica e breve aparecerá o quarto volume. Tivemos de Sergio Milliet o seu Diário Crítico, que certamente continuará para sempre. Apesar de uma dura pomposidade ocasional, Lins é considerado um dos melhores críticos, especialmente da atual produção brasileira, que êle sabe comparar com a literatura de outros países. A série total é indispensavel ao estudante da literatura brasileira. Sergio Milliet julga-se um pouco um Gide paulista, mas o fato é que seu trabalho é comparavel em sensibilidade e equilíbrio ao de Gide, mesmo sem o crédito deste último, e é mais universal, incluindo muitas idéias interessantes sôbre arte.

A edição em dois volumes do professor e poeta Manuel Bandeira, das poesias de Gonçalves Dias e no gênero, o trabalho mais notável do ano de 1944 (onde se encontra crítica e educação literária). As poesias colecionadas de Manuel Bandeira estão sendo editadas agora, assim como o volume de luxo das suas traduções de poesias de outros idiomas.

Para o estrangeiro, a quem aliás foi destinado o livro Poetas do Brasil, por Jayme de Barros é uma facil e agradável introdução à história da poesia brasileira, pondo em destaque os contemporãneos. Ésse trabalho foi originalmente apresentado no Uruguai em forma de uma série de conferências. Em estilo leve, não tem pretenção a ser uma obra completa e nem possue o aparato de documentações, mas certamente não significa condenação a um livro, declara-lo util.

Duas obras escritas por mineiros, com grande amor por seu estado, são entretanto, muito diferentes entre si. Carlos Drummond de Andrade, poeta modernista e o braço direito do Ministro Capanema no ministério de Educação, publicou Confissóes de Minas, uma miscelânea de prosa, que na realidade pouco tem a ver com o estado de Minas. Apesar do excelente estilo, constituiu algo de decepcionante para os seus muitos admiradores. Alceu de Amoroso Lima (dessá vez abandonando o pseudônimo literário de Tristão de Athayde) publicou com data de 1945, embora no começo de Dezembro, Voz de 
Minas. Foi um dos primeiros frutos da casa editora AGIR da qual é interessado. Voz de Minas pode ser considerado um belo livro, construido com base e brilhantemente escrito. $\mathbf{E}$ o primeiro de cinco análises sôbre as regiões do Brasil, mas é certamente o que foi escrito com mais entusiasmo, porque a psicologia e sociologia de Minas, sua moral e sua tradição, cuidadosamente estudadas em separado, são exatamente o gênero de cultura e personalidade que despertam a simpatia do autor. A missão de Minas no país é sua missão particular. Tenta obter justiça imparcial, mas isso acontece ser uma página de crítica após 64 de louvores, e nessa única página diz que os mineiros têm os defeitos das suas virtudes, que são muitas e importantes. Para classificar o livro na corrente da literatura mundial, teriamos que voltar ao Germania de Tacitus, ao La Bruyère, e descer até Salvador Madariaga e D. W. Brogan. Desconfia-se dessa lógica tão clara, e fica-se fatigado com tantas repetições (o mineiro, diz o autor, gosta de repetir), mas, é um livro notável. Si está de acordo com a psicologia do mineiro ou si o mineiro foi usado apenas como pretexto para o autor apresentar sua filosofia própria, é uma questão duvidosa.

Em fins de 1944, um autor de grande influência que nunca havia escrito antes um livro, deu-1nos cinco contos sob o título de Vila Feliz. Anibal Machado é presidente da Associação Brasileira de Escritores, e sua inteligência perspicaz e liberalismo destemido são muito apreciados. Foi comparado a Sócrates porque, sem escrever possuia grande influência; a Valéry, pelo fato de escrever pouco, e atualmente a Gogol e Maupassant devido à essas cinco histórias. O louvor é excessivo como frequentemente acontece no Brasil. Entretanto, o livro firma-se imediamente entre os melhores de contos brasileiros. São realmente trechos de antologia; um ao menos, já estava numa antologia quando e volume foi publicado. Deveriam ser saboreados por leitores americanos, no setı agradável original ou numa tradução esmerada. Variam de uma extravagância sempre humana, à uma intensidade trágica que nunca perde contato com a terra. Lágrimas e risos, meus amigos... e arte também.

William Rex Crawford, Rio de Janeiro. (Embajada de los Estados Unidos.) 
